\title{
A realidade dos assentamentos rurais por detrás dos números
}

\author{
Sonia Maria Pessoa Pereira Bergamasco
}

$\mathrm{M}$

UITO MAIS do que uma avaliação quantitativa, o I Censo da Reforma Agrária do Brasil traz à tona uma série de questões que extrapolam a simples leitura dos números.

A temática da reforma agrária no Brasil tem sido uma constante desde os anos 50 e 60 , em que aparecia como solução para as questões nacionais. O golpe militar de 64 , ao contrário do que se poderia esperar, institucionalizou a questão por meio da promulgação, em novembro de 1964, do Estatuto da Terra. Letra morta para a resolução dos problemas agrários do país, o Estatuto da Terra respaldou um longo processo de colonização, em especial na região Norte e CentroOeste, por meio da implantação de assentamentos de colonos do Sudoeste e do Sul.

Os movimentos sociais rurais, em efervescência no pré-64, foram duramente reprimidos, e a opção do governo militar, além da colonização, se volta à modernização da agricultura por meio de incremento ao uso de insumos químicos e mecânicos, deixando sem alteração a concentrada estrutura fundiária. Os resultados perversos desta modernização podem ser constatados pela formação de uma classe de assalariados rurais com baixíssimo poder de compra, pelo desemprego, especialmente o desemprego sazonal, pela precariedade das condições de trabalho e pela exclusão social, o que levou mais de 28 milhões de pessoas a deixarem o campo em direção às cidades, entre 1960 e 1980 . Esta precarização das condições de vida e de trabalho de milhões de pessoas resultou no fortalecimento da organização política dos trabalhadores.

Nos anos 80 e 90, os movimentos de trabalhadores rurais ganham ímpeto, tanto no campo como nas cidades. A problemática da reforma agrária garantindo o acesso à terra torna-se palavra de ordem na sociedade brasileira.

Com diferentes matizes e com apoios e contra-apoios, a questão da reforma agrária volta a ocupar a agenda política do país. A partir de meados dos anos 80 registra-se, de forma lenta e irregular, a implementação de assentamentos rurais em todos os Estados da Federação. Como afirma Norder (1997), são projetos criados muito mais para resolver situações de conflitos localizados do que situações de pobreza e exclusão social, ou mesmo para resgatar o potencial produtivo da agricultura familiar.

As denúncias contra os massacres de trabalhadores rurais, aliadas à realização 
do III Congresso Nacional do Movimento dos Trabalhadores Rurais Sem Terra (MST), em 1995, que decide pelo incremento das ocupações, faz emergir com muita ênfase o debate sobre a reforma agrária no seio da sociedade brasileira.

A palavra de ordem "ocupar, resistir e produzir", base de uma intensa mobilização em todos os cantos do país, ganha publicidade tanto nacional como internacional. Ao Estado resta dar respostas por meio da implementação de assentamentos e da desapropriação de terras improdutivas.

Inicia-se uma grande batalha por parte do governo federal, na busca de melhores condições jurídicas que pudessem garantir os processos desapropriatórios de forma mais rápida e efetiva. Isto porque os parcos instrumentos de reforma agrária foram sendo corroídos no decorrer dos tempos. O Estatuto da Terra, marco jurídico importante para implementação de uma reforma agrária no país, teve sua existência simultânea à destruição dos direitos políticos que garantiriam sua implementação. Mesmo sua retomada em 1985, com o estabelecimento do Plano Nacional de Reforma Agrária (PNRA), é frustada pela pressão da contra-reforma, representada pelo latifúndio conservador e arcaico, como por exemplo a União Democrática Ruralista (UDR).

Com algumas vitórias jurídico-legais, o atual governo de Fernando Henrique Cardoso passa, a partir de 1996, a publicizar o resultado de suas ações, indicando o cumprimento das metas previstas (1) em termos de número de famílias assentadas. A partir daí estabelece-se uma polêmica em torno destes números entre o governo federal, em especial o Instituto Nacional de Colonização e Reforma Agrária (Incra), e o Movimento dos Trabalhadores Rurais Sem Terra (MST), este último com indicadores bem aquém daqueles apresentados.

Foi exatamente essa polêmica que levou o Incra a encomendar o I Censo da Reforma Agrária do Brasil, cuja responsabilidade recaiu sobre as universidades brasileiras, sob a coordenação da Universidade de Brasília.

Particularmente, fui protagonista desse processo na função de supervisora do censo no Estado de São Paulo. Foi, sem sombra de dúvida, um imenso e complexo trabalho. Vinte e nove universidades, envolvendo 1.800 estudantes em todos os Estados brasileiros, assumiram este encargo, cujo objetivo era o de atualizar os cadastros do Incra, identificar novas famílias e outras informações adicionais, como sexo, idade, escolaridade, estado civil etc. Além disso, delineou-se um levantamento sócio-econômico por meio de dados amostrais.

Neste texto, juntamente com uma impressão pessoal dos dados apresentados no censo, pretendemos, à luz desta quantificação, mostrar que a construção de um novo modo de vida pelos assentados extrapola a simples leitura dos números. Embora não negando sua importância, há que pensar que o censo enquanto tal não expressa a realidade dos assentamentos com seus problemas, suas dificuldades, suas estratégias de manutenção na terra, enfim, seu entendimento enquanto "espaço social produzido". 


\section{O que os números revelam}

Antes de iniciar uma leitura mais apurada nos números revelados pelo censo, cumpre registrar algumas das preocupações apontadas pelos supervisores, por ocasião do treinamento. Estas já foram motivo de uma resenha publicada na revista Estudos: sociedade e agricultura, de abril de 1997 ( $\mathrm{n}^{\circ}$ 8), assinada pelo professor Roberto José Moreira, supervisor do censo no Rio de Janeiro.

Uma primeira ordem de questões diz respeito às restrições impostas pelo Incra ao manter a mesma sistemática de acompanhamento que já vinha implementando por meio do Sipra (Sistema de Informações de Projetos de Reforma Agrária). Isso limitou os coordenadores e supervisores do censo a colocar questões importantes que não apareciam no formulário do Sipra, bem como de implementar outros arranjos.

Algumas questões metodológicas de grande importância foram ainda motivo de polêmica no treinamento dos supervisores: os conceitos para a caracterização da situação do assentado, em especial as categorias agregados e irregular; as dificuldades nas situações em que as áreas urbanas se confundiam com os assentamentos; o tratamento a ser dado e a caracterização dos projetos de regularização fundiária; a não-coleta dos preços praticados nos assentamentos, para o caso do levantamento por amostra, certamente acarretaria distorções na análise da renda que não seriam resolvidas pela imputação de preços médios estaduais; a questão das formas cooperadas e coletivas de produção não seriam captadas adequadamente tendo em vista que a coleta de dados se daria somente nas formas parcelares e familiares (Moreira, 1997).

Outra ordem de questões se refere à operacionalização do trabalho, tais como: o pequeno prazo reservado à tarefa de campo; as baixas estimativas de custos; as dificuldades de transporte; o período do ano, que coincidiu com a época das chuvas, o que dificultou sobremaneira o acesso a alguns assentamentos; a falta de apoio de alguns técnicos a fim de que os estudantes pudessem chegar aos assentamentos, dentre outras.

\section{O número de familias assentadas}

O censo quantificou o número de famílias assentadas até 31 de outubro de 1996. Entretanto, só foram enquadrados os assentamentos sob a égide do Incra. Nesse sentido, foi excluída uma grande parcela de assentamentos implementados por políticas estaduais ou mesmo municipais. Isso causou problemas na quantificação. No Estado de São Paulo, por exemplo, registraram-se assentamentos (em especial os da região do Pontal do Paranapanema) que, embora tenham sido implantados em áreas resgatadas pelo governo federal, encontram-se sob a coordenação do governo estadual.

O censo apurou um total de 161.556 famílias beneficiárias em 1.460 projetos de assentamentos distribuídos por 26 estados da Federação. Os Estados do Maranhão 
e do Pará são os que apresentaram maior contingente de famílias assentadas. Este fato vem confirmar uma territorialização da reforma agrária (Bergamasco \& Norder, 1996 e Fernandes, 1996), reeditada dos processos de colonização do regime militar, reforçada pelas respostas do Estado aos conflitos, que têm maior incidência nas áreas de fronteira.

Considerando-se apenas o número de famílias assentadas no governo Fernando Henrique Cardoso, no período 95-96, pode-se constatar também uma preponderância de assentamentos nas regiões Norte e Nordeste, o que indica não ter havido qualquer ruptura significativa com o tipo de política agrária implementada pelos governos anteriores, qual seja, a atuação prioritária em áreas de conflitos sociais passíveis de gerar mortes, como as de Corumbiara e Eldorado de Carajás.

É certo que o governo atual teve uma participação significativa no número de famílias assentadas em relação aos governos anteriores. Registrou-se um total de 55.692 no período 95/96. Como já foi citado, as metas do governo Fernando Henrique Cardoso seriam o assentamento de 40 mil famílias em 1995 e 60 mil em 1996. Neste sentido, as 55.692 famílias, embora contadas até 31 de outubro de 1996, estariam aquém das metas relativas aos dois anos, que seriam de 100 mil famílias.

Entretanto, é importante reafirmar que desta totalização, embora indique resultados negativos em relação às metas fixadas, há que buscar na complexidade desses processos situações outras que estariam a indicar condições favoráveis de análise. São dados estratégicos, que desaparecem quando se analisam médias ou grandes cadastros. Só para exemplificar, pode-se tomar dados de alguns municípios da região do Pontal do Paranapanema a fim de avaliar os impactos causados pela implantação dos assentamentos (tabela 1). Num simples exercício aritmético podese registrar um significativo acréscimo no número de moradores da área rural em alguns municípios. A população rural do município de Presidente Venceslau em 1991, por exemplo, representava apenas $4,8 \%$ do total. Eram 1.732 pessoas vivendo em 480 domicílios rurais. $\mathrm{O}$ assentamento de 409 famílias representou um significativo acréscimo no número de moradores da área rural desse município.

Estabelece-se nesse cenário um novo e intenso processo de socialização que vai repercutir em novos espaços sociais, econômicos, culturais e políticos. Apreender essas mudanças permite ir além dos dados globalizados; permite apreender as dimensões do novo em suas especificidades.

\section{Indicadores sociais}

Algumas informações contidas no censo permitem identificar a persistência de graves problemas sociais ainda sem equacionamento. Isso reafirma que "a conquista da terra não significa que seus ocupantes passem a dispor da necessária infraestrutura social (saúde, educação, transporte, moradia) e produtiva (terras férteis, assistência técnica, eletrificação, apoio creditício e comercial)..." (Bergamasco \& Norder, 1996). 
Tabela 1

População urbana e rural, número de domicílios e famílias assentadas em alguns municípios do Estado de São Paulo, 1991/97

\begin{tabular}{|c|c|c|c|c|c|}
\hline \multirow{2}{*}{ Município } & \multicolumn{2}{|c|}{ População } & \multirow{2}{*}{$\begin{array}{l}\text { Pop. } \\
\text { Rural } \\
\%\end{array}$} & \multirow{2}{*}{$\begin{array}{c}\text { Número } \\
\text { Domicílios } \\
\text { Rurais }\end{array}$} & \multirow{2}{*}{$\begin{array}{l}\text { Número } \\
\text { Famílias } \\
\text { Assentadas }\end{array}$} \\
\hline & Urbana & Rural & & & \\
\hline Álvares Machado & 15.387 & 3.478 & 18,4 & 865 & 42 \\
\hline Caiuá & 1.460 & 1.881 & 56,3 & 451 & 180 \\
\hline Euclides da Cunha & 6.340 & 3.224 & 33,7 & 697 & 807 \\
\hline Mirante do Paranapanema & 10.545 & 4.634 & 30,5 & 1.003 & 1.175 \\
\hline Presidente Bernardes & 10.875 & 5.426 & 33,2 & 1.207 & 298 \\
\hline Presidente Venceslau & 34.388 & 1.732 & 4,8 & 480 & 409 \\
\hline Rancharia & 23.076 & 3.837 & 14,2 & 412 & 244 \\
\hline Santo Anastácio & 19.051 & 3.028 & 13,7 & 762 & 38 \\
\hline Teodoro Sampaio & 26.921 & 22.315 & 45,3 & 3.612 & 415 \\
\hline
\end{tabular}

Fonte: I Censo da Reforma Agrária no Brasil e FIBGE (1961)

\section{Escolaridade/educação}

As médias apresentadas para os assentamentos espalhados pelo Brasil apontam para $39,4 \%$ de analfabetos/alfabetização incompleta, e o mesmo porcentual de titulares com o ensino primário incompleto. Nos Estados do Sul, o analfabetismo dos titulares é de quase 14\% e, no Estado de São Paulo registraram-se 29,7\% de titulares que não chegaram a completar o ensino primário. O que mais chama a atenção é o fato de que esta situação não vem sendo alterada: 97,6\% do total de titulares dos lotes de assentamentos no Brasil estão fora de qualquer programa de estudos, o que indica a não existência de um programa minimamente consistente de educação de adultos nos assentamentos brasileiros.

Nesse contexto, ressalta-se a omissão do Estado. As respostas dadas pelo governo à mobilização dos trabalhadores rurais no IV Grito da Terra (Brasil, 1997) são testemunha desta omissão. "Na área de educação, nenhum avanço significativo sequer foi vislumbrado, a não ser nas promessas já velhas que estão para ser concretizadas. A abertura para um debate sobre uma educação voltada à realidade rural foi simplesmente negada. Igualmente, o governo federal se nega a discutir um programa amplo de redução e eliminação do analfabetismo no Brasil, deixando esta tarefa para os municípios" (Boletim do Deser, 1997).

A grande maioria (80\%) dos beneficiários entrevistados afirmou não possuir outra habilidade não-agropecuária, e os quase $20 \%$ restantes, ou seja, os que disseram ter outra habilidade, são na maioria pedreiros, motoristas e garimpeiros. Esses dados apontam para o caráter incompleto dos assentamentos, para a ausência de 
políticas públicas complementares destinadas à promoção do desenvolvimento sociocultural e técnico-econômico dos projetos. Mesmo considerando que quase $50 \%$ das famílias entrevistadas chegaram ao assentamento após 1990, e que nada menos que $24,5 \%$ do total de famílias são pré-assentadas e com situação ainda não regularizada, a inconsistência das políticas públicas para os assentamentos se expressa nas limitações observadas na estrutura produtiva e na capacidade de consumo doméstico das famílias assentadas. A ausência de programas educacionais mais amplos, ou ainda sua articulação com o aumento da capacidade técnica e produtiva desses produtores nesse sentido, é uma clara demonstração dessa evidência.

Deslocando-se o foco de análise para o interior dos assentamentos, em alguns núcleos pode-se registrar uma efervescente organização, em especial entre as mulheres, por meio das comissões de educação que propõem, reivindicam, constroem etc. elementos para garantir a formação e o futuro, principalmente, das crianças e dos jovens. O próprio MST tem um setor de educação bastante atuante, em que é peculiar a preocupação com a formação dos jovens em programas técnicos em áreas como o cooperativismo, dentre outras.

\section{Sexo, idade e estado civil}

Apenas para registrar o esperado, os beneficiários da reforma agrária totalizam $85,6 \%$ de homens. O acesso das mulheres aos benefícios da reforma agrária continua, apesar das mudanças da Constituição de 88 , uma situação de exceção. A análise da realidade tem mostrado "no processo de construção das relações sociais nos assentamentos, marcas da violência de gênero, presentes em vários momentos: no projeto de assentamento apresentado pelo Estado, cuja dimensão patriarcal aparece na criação da figura do cadastrado, reservada ao homem; na delimitação de espaços masculinos e femininos no interior dos assentamentos; no alijamento das mulheres do processo decisório" (Ferrante, 1993, 1995; Bergamasco, 1994, 1995).

Quase metade dos titulares dos lotes de assentamentos, no Brasil, possui entre 36 e 57 anos; somam $48,4 \%$ do total. Se acrescentarmos os titulares com idade entre 23 e 35 anos, vamos obter uma população em idade ativa ( 23 a 57 anos) da ordem de $76,9 \%$. Em $82,5 \%$ dos casos, os titulares são casados legalmente ou constituem relações estáveis, contra $3,8 \%$ de separados, desquitados e divorciados, $3,5 \%$ de viúvos e $10,1 \%$ de solteiros.

Em termos gerais, trata-se de uma força de trabalho em idade ativa, pouco qualificada para atividades fora da agropecuária, instalada há pouco tempo no assentamento e destituída de programas de capacitação técnica, principalmente para o aperfeiçoamento de sua produção agropecuária (Bergamasco, Norder \& Villa, 1997).

\section{Ocupação anterior}

A grande maioria dos beneficiários já trabalhou na agricultura. Cerca de 19,7\% deles foram arrendatários, parceiros e foreiros; 16,6\% foram posseiros e $9,1 \%$ ocu- 
pantes; $12,4 \%$ vendiam sua força de trabalho na forma de assalariamento. Do total, apenas 16,3\% eram proprietários anteriormente. Assim, os assentamentos representam uma transformação no tipo de relações sociais nas quais estavam inseridas estas famílias; uma transformação na forma de uso da terra; uma transformação das práticas de produção agropecuária. Representam uma nova forma de produzir, um novo controle sobre o tempo de trabalho, a realização de atividades que até então não faziam parte de suas atribuições nas relações sociais anteriores. A redefinição das relações sociais em torno da posse da terra pode ser compreendida como um ponto de partida para a redefinição de um conjunto de outras práticas sociais.

\section{Cultura material e habitação}

Os indicadores da cultura material, tomados apenas em três itens principais - geladeira, fogão e televisão - mostram uma porcentagem relativamente baixa entre os assentamentos brasileiros. Apenas 9,5\% possuem geladeira, 28,9\% possuem fogão e $13 \%$ possuem televisão.

$\mathrm{Na}$ questão habitacional, registra-se predominância na construção de casas de madeira, $31,9 \%$ contra $22,9 \%$ de alvenaria. O índice de casas de taipa supera a construção em alvenaria, atingindo $28,2 \%$, sendo sua incidência maior na região Nordeste. As casas de madeira são encontradas na região Sul, enquanto as de alvenaria são mais comuns na região Sudeste. Apenas $28,8 \%$ consideram "boa" sua situação habitacional, para $38,1 \%$ que a consideram "regular" e 24,6\% que reconhecem estar morando em situação "precária". O potencial da demanda pelo aperfeiçoamento habitacional nos assentamentos, portanto, é elevado, e isso representa mais um segmento econômico a ser constantemente impulsionado por uma demanda individualmente pequena, mas presente em um elevado número de famílias.

Acrescenta-se a este o fato de que apenas $20 \%$ das famílias beneficiárias contam com energia elétrica.

Novamente pode-se apontar para a falta de uma política adequada ao desenvolvimento desses projetos por meio de programas habitacionais e de energia elétrica. A despeito disso, a construção e a reconstrução de um novo modo de vida pelos assentados inclui, em um primeiro momento, a implantação de sua moradia, quer de alvenaria, madeira ou taipa, e de formas as mais distintas: mutirão, familiar, troca de favores etc.

\section{Saúde}

No campo da saúde pública, conta-se atualmente com uma precariedade nesses serviços. As informações do censo nos permitem chegar às seguintes constatações: apenas $1 \%$ dos beneficiários sabem que possuem diabetes. Além disso, a violenta situação epidemiológica vigente é marcante em alguns Estados, como é o caso de Rondônia, onde mais de um terço das famílias foram atingidas pela malária em apenas um ano, ou ainda o caso da Bahia, onde 20,8\% das famílias entrevistadas deparou-se com problemas de verminoses. 
O Boletim do Deser sobre o IV Grito da Terra traz uma análise sobre as respostas do governo federal em relação às reivindicações dos trabalhadores rurais em termos de saúde. "No fundo tudo vai depender dos municípios e dos Estados. O governo continuará investindo a mesma quantia, ou seja, se depender do Ministério da Saúde, o Serviço Unificado da Saúde, o SUS, continuará do jeito que está”.

\section{Indicadores econômicos}

\section{Renda}

Apesar da inconsistência das políticas governamentais para os assentamentos a curto e a médio prazos, o acesso à terra permite uma reorganização social dessas famílias de trabalhadores rurais, por dois fatores: a) a abertura de um espaço para a construção habitacional; e b) o aumento na disponibilidade familiar de alimentos por meio da prática do autoconsumo. Entretanto, é evidente que a renda monetária agropecuária constitui o principal objetivo dessas famílias, cuja idade dos titulares, como foi visto, não permite atualmente, em sua grande maioria, a aposentadoria pela previdência social. A atividade que mais intensamente e freqüentemente permite a essas famílias atingir um padrão de vida que as coloque claramente em uma situação de não-pobreza é, portanto, a geração da renda agropecuária.

A partir de meados da década de 80 , a polêmica do cálculo da renda ou da avaliação econômica dos assentamentos rurais tem sido motivo de diversas pesquisas.

A primeira delas, divulgada pelo BNDES em 1987, concluiu pelo fracasso da reforma agrária no Brasil apontando que a maioria das famílias assentadas tem renda inferior a dois salários mínimos, que há uma forte concentração de renda entre elas e que parte significativa vive do trabalho assalariado e não da renda dos lotes. A crítica à pesquisa do BNDES, coordenada por Castro (1992), é de que os parâmetros por ele utilizados se inserem em um contexto de "empresas rurais", deixando de lado especificidades necessárias ao cálculo da renda em uma agricultura familiar.

Alguns anos depois, em 1991, a FAO lança uma segunda pesquisa utilizando outras categorias analíticas, em especial uma combinação de diversas fontes de renda. Esta não foi limitada apenas ao retorno monetário resultante da comercialização dos produtos agropecuários do assentamento. Acrescentou-se a este o autoconsumo, $\mathrm{o}$ assalariamento e a valorização patrimonial. A renda encontrada na pesquisa da FAO foi de 3,7 salários mínimos mensais por família em termos de média nacional, havendo, no entanto, uma variação regional, conforme pode ser visto na tabela 2. As regiões Sul e Sudeste apresentam os maiores índices de renda, em detrimento da região Nordeste, cujo índice é o menor.

Mais recentemente, a Confederação Nacional da Agricultura (CNA) encomendou ao Instituto Vox Populi uma pesquisa de avaliação dos assentamentos rurais. Os resultados mostram uma renda familiar média mensal da ordem de R \$ 132,14, o que estaria muito perto de um salário-mínimo mensal por família. A CNA alar- 
deou na mídia um quadro extremamente desolador dos assentamentos brasileiros, acrescentando, além da baixa renda, outros indicadores de condições de vida. Graziano da Silva (1996), utilizando dados das PNADs de 1993, em resposta aos resultados da pesquisa da CNA, mostrou que os dados da mesma em nada diferem das condições gerais da população rural brasileira (ver tabela 3).

Tabela 2

Renda média familiar por região nos assentamentos rurais brasileiros, 1991

\begin{tabular}{|l|c|}
\hline \multicolumn{1}{|c|}{ Regiões } & Renda média familiar \\
\hline Centro-Oeste & 3,85 \\
Nordeste & 2,33 \\
Sudeste & 4,13 \\
Sul & 5,62 \\
Brasil & 3,70 \\
\hline
\end{tabular}

Fonte: FAO/MARA-1991

Tabela 3

Comparação das condições dos assentamentos (pesquisa CNA/Vox Populi) com as condições gerais da população rural (PNAD, 1993)

\begin{tabular}{|l|c|c|}
\hline \multicolumn{1}{|c|}{ Especificação } & Pesquisa CNA (\%) & PNAD/93 (\%) \\
\hline Coleta de Esgoto & 33 & 40 \\
fossa e outros & 1 & 1 \\
rede geral & 66 & 59 \\
nenhuma & & \\
& 11 & 12 \\
Água & 38 & 46 \\
rede geral & 80 & 67 \\
Energia Elétrica & 33 & 25 \\
rádio & 132,14 & $129,65\left(^{(*)}\right.$ \\
TV & & \\
renda & & \\
\hline
\end{tabular}

Fonte: Graziano da Silva, 1996

(*) Famílias com renda de até três salários mínimos mensais. 
A renda obtida pelo levantamento amostral do I Censo da Reforma Agrária traz uma composição em que se incluem salários, remessas diversas, aposentadorias, serviços prestados e outras rendas, no caso da unidade familiar. Os beneficiários que compartilham de recursos captados de forma coletiva tiveram sua parte acrescida na renda familiar. Nesse sentido, a renda monetária seria a soma das diversas rendas da família adquiridas de forma associativa ou familiar.

"Em termos gerais e nacionais, somando-se todos os itens pode-se perceber que há famílias de assentados que chegam a auferir perto de trinta salários mínimos por ano, extraídos de diferentes fontes de renda" (I Censo da Reforma Agrária, 1997). Isto vai significar cerca de 2,5 salários mínimos mensais em média.

O censo apresenta ainda a renda monetária associativa média no sentido de auferir uma forma extra de renda. Para sua composição foram incluídas as rendas advindas de agricultura, pecuária, trabalho assalariado, serviços prestados e outras rendas. Os dados mostram uma preponderância da "agricultura" e "pecuária" na composição da renda associativa das regiões Sul e Sudeste. Entretanto, a renda monetária associativa é sempre menor quando comparada à renda da família, principalmente no item "outras rendas".

No entanto, como já foi afirmado anteriormente, existiram problemas na coleta de informações referente à obtenção da renda. Estes problemas são também explicitados no relatório do censo.

Norder (1997) chama a atenção para os problemas metodológicos que se registram nas avaliações dos assentamentos rurais, principalmente no "cálculo da renda", tais como: "l) a definição da abrangência do conceito de renda, a forma de mensuração do autoconsumo produtivo ou alimentar, e demais formas de ingresso monetário como o assalariamento externo e a previdência social; 2) a complexidade na formação dos custos de produção e a diversidade na comercialização da produção; 3 ) a valorização profissional da área pelo trabalho; 4) a utilização de relações informais familiares e comunitárias de trabalho, como o mutirão, a ajuda mútua, a troca de dias, reduzindo a necessidade de pagamento de trabalho adicional em dinheiro, alterando assim os custos de produção e, portanto, a renda; 5 ) a tênue articulação com outros indicadores sociais e econômicos".

A análise desses requisitos nos leva à conclusão de que a auferição da renda junto a unidades familiares de produção exige cuidado e tempo, o que foi impossível na coleta de dados por ocasião da realização do censo.

\section{Tecnologia}

Os dados amostrais do censo podem dar idéia do nível tecnológico dos assentamentos rurais no Brasil por meio de alguns indicadores. Cerca de $20,2 \%$ dos assentados utilizam-se da mecanização; $38,7 \%$ usam sementes selecionadas em sua produção; 11,7\% fazem correção do solo com calcário e adubos. Embora tenha-se registrado diferenças regionais, em alguns casos bastante extremadas em favor das 
regiões Sul e Sudeste, as médias nacionais apresentam níveis coerentes com o panorama brasileiro.

\section{Crédito}

Para análise do crédito do Procera, os dados amostrais indicam que apenas 26,2\% dos beneficiários receberam o Procera-custeio e 24,3\% o Procera-investimento. Nas análises regionais percebe-se uma relativa concentração da obtenção do Procera nas regiões Sul e Sudeste.

Cabe aqui, mais uma vez, chamar a atenção para a falta de uma política efetiva de crédito para a reforma agrária. Embora ela exista, seu alcance é ainda bastante precário. Além das dificuldades de acesso ao mesmo, pode-se constatar que os recursos dispendidos pelo governo são ainda excessivamente limitados. Entre os anos de 1987 a 1995 foram contratados junto ao Procera um total de US\$ 380.576.832, considerando-se diferentes fontes: Bacen, BNDES, BB/Incra etc. (Oliveira, 1996).

A análise do crédito relativo ao Bacen, apresentada por Oliveira (1996), reafirma a concentração regional, qual seja: do total de recursos concedidos, cerca de 80\% ficaram com os Estados do Sul e do Sudeste.

\section{Considerações finais}

Os assentamentos rurais brasileiros representam, sob o ponto de vista das famílias hoje assentadas, uma nova forma de produzir, um novo controle sobre o tempo de trabalho, a realização de atividades que até então não faziam parte de suas atribuições nas relações sociais anteriores. A redefinição das relações sociais em torno da posse da terra pode ser compreendida como ponto de partida na redefinição de um conjunto de outras práticas sociais.

Isso aponta para a necessidade de observação sistemática das novas relações com o mercado e com muitas outras instituições envolvidas na produção agropecuária. Na parceria, no arrendamento e, principalmente, no trabalho assalariado, as diversas atividades que compõem o processo produtivo eram até então controladas pelo fazendeiro/proprietário fundiário. Agora, passam ao controle direto dos agricultores assentados.

Estas alterações socioculturais e econômico-institucionais, no entanto, nem sempre contam com um adequado suporte das políticas públicas, uma decorrência das próprias relações de forças políticas presentes no interior do Estado. Assim, a construção/reconstrução das relações sociais adquire um caráter histórico.

Daí as dificuldades de apreender esta realidade, que é dinâmica, por meio de levantamentos estatísticos com cortes horizontais, sem correr o risco de ahistoricizá-la. 
Nota

1 De acordo com o documento da presidência da República intitulado Reforma agrária: compromisso de todos (1997), as metas do governo Fernando Henrique Cardoso seriam o assentamento de 40 mil famílias em 1995, 60 mil em 1996, 80 mil em 1997 e 100 mil em 1998, totalizando 280 mil famílias assentadas.

Bibliografia

BERGAMASCO, Sonia Maria Pessoa Pereira. "A família nos assentamentos rurais: trajetórias e conquistas”. In: Seminário Internacional Mulher, Família e Desenvolvimento Rural, Anais, Santa Maria, 1994.

"Mulheres assentadas: trajetórias e conquistas". In: Reunião Anual da SBPC, 47, São Luiz, MA, 1995.

BERGAMASCO, Sonia Maria Pessoa Pereira; NORDER, Luiz Antonio Cabello \& VILLA, Fábio Alexandre. Os impactos regionais dos assentamentos rurais do Estado de São Paulo. Campinas, Feagri/Unicamp, 1997 (Relatórios de Pesquisa I e II).

BERGAMASCO, Sonia Maria Pessoa Pereira; NORDER, Luiz Antonio Cabello. O que são assentamentos rurais? São Paulo, Brasiliense, 1996 (coleção Primeiros Passos, 301).

“O recente processo agrário brasileiro: o ressurgimento da UDR e a rearticulação das demais entidades ruralistas". In: Encontro da Apipsa, 17, Campina Grande, nov. 1996 (mimeo.).

BOLETIM DO DESER. IV Grito da Terra mobiliza os trabalhadores. n 81 , Curitiba, mai. 1997.

BRASIL, PRESIDENTE. Reforma agrária - compromisso de todos. Brasília, Presidência da República, Secretaria de Comunicação Social, 1997.

CASTRO, M. H. Reforma agrária e pequena produção. Campinas, IE/Unicamp, 1992 (tese de doutorado).

FERNANDES, Bernardo Mançano. MST: formação e territorialização. São Paulo, Hucitec, 1996 (coleção Geografia: teoria e realidade, 37).

FERRANTE, Vera Lucia Botta. Las mujeres asalariadas en la lucha por la tierra. IN: Congreso Internacional de Ciencias Antropologicas y Etnologicas, 12, Resumenes, Cuidad de Mexico, 1993, p.51.

"La lucha por la tierra tiene dos sexos". In: VALDES, X. et alii. Mujeres: relaciones do gobierno en la agricultura. Santiago del Chile, Cedem, 1995.

GRAZIANO DA SILVA, José. Casa, comida e trabalho: qual é a alternativa à reforma agrária? Campinas, IE/Unicamp, 1996 (mimeo.). 
MOREIRA, Roberto José. "Metodologias da reforma agrária: o censo e o projeto Lumiar”. Estudos: sociedade e agricultura, CPDA/UFRJ, 8: 163:77, abr. 1997.

NORDER, Luiz Antonio Cabello. Assentamentos rurais: casa, comida e trabalho. Campinas, IFCH/Unicamp, 1997 (dissertação de mestrado).

OLIVEIRA, Mauro Marcio. Procera - Relatório Final da Consultoria. Brasília, 1996 (acordo Incra/PNUD).

Resumo - A proposta deste texto é discutir o complexo processo de constituição dos assentamentos rurais brasileiros à luz dos dados apresentados pelo I Censo da Reforma Agrária do Brasil. Pretende-se mostrar que a construção de um novo modo de vida pelos assentados extrapola a simples polêmica dos números, revestidos que são de relatividades. Embora não negando sua importância, há que pensar que o censo, enquanto tal, não expressa a realidade dos assentamentos com seus problemas, suas dificuldades, suas estratégias de manutenção na terra, enfim, seu entendimento enquanto "espaço social produzido". No entanto, a publicação desse censo remete a um sem número de questões acerca do grave problema agrário brasileiro.

Abstract - The purpose of this text is to discuss the complex process of the Brazilian agrarian camp formation under the account of the data presented by the I Censo da Reforma Agrária do Brasil. This text intends to show that the building of a new way of life by the settled people is very beyond the mere polemic of the numbers, all entailing relativity. Although its importance can not be denied, it must be observed that the census itself does not show the reality of the encampments: their problems, their difficulties, their strategies of permanence in the areas, and their conviction as "social produced space". The publication of this census, however urges us to the countless issues involving the very serious problem of land property in Brazil.

Sonia Maria Pessoa Pereira Bergamasco é professora titular da Faculdade de Engenharia Agrícola da Unicamp. 